\title{
Public private partnerships for climate change mitigation - An Indian case
}

\author{
Dolla Tharun, and Boeing Laishram* \\ Infrastructure Engineering and Management Division, Department of Civil Engineering, Indian \\ Institute of Technology Guwahati, Guwahati - 781 039, India
}

\begin{abstract}
Cities are one of the major contributors to greenhouse gas emissions. Climate change poses serious threat to urban infrastructure, quality of life, and entire urban systems. Cities need to adopt an integrated approach for improvement of city services in order to adapt to climate change and reduce their greenhouse emissions. However, the magnitude of investment required to bridge the widening infrastructure service provision demand-supply gap along with the additional investment to mitigate climate change demands the need to look for innovative financing solutions. Private investments through public private partnership (PPP) route offer an innovative mechanism for meet both the goals of infrastructure development and climate change mitigation. Private parties in PPP, however, focuses on the project economics only though they have the potential to provide innovative technical, financial and managerial solutions. The paper aims to answer the question how to integrate climate change mitigation objective in procurement process of PPP projects. The study has focused only on PPP projects in Municipal Solid Waste Management sector. The integration of climate change mitigation objective has been through design of a modified procurement protocol which promote private sector to devise project structure that fulfil both the objectives of climate change mitigation and provision of quality infrastructure services.
\end{abstract}

\section{Introduction}

Cities are the major contributors to greenhouse gas emissions. Most of the economic activities are concentrated in urban areas; as a result cities have a major role in climate change. Cities consume as much as $80 \%$ of energy production worldwide and account for a roughly equal share of greenhouse gas emissions. Besides, the relation between greenhouse gas emissions and how the electricity is produced and how energy is used in buildings and transit, the other urban services such as, water treatment, wastewater production, and solid waste generation are all linked among themselves and with greenhouse gas emissions as well. With development, most of the greenhouse gas emissions from cities will be driven more by the energy services for lighting, heating and cooling and less by the industrial

\footnotetext{
* Corresponding author: boeing@iitg.ernet.in
} 
activity. In addition to this, urban population is expected to double by 2030 and the city built-up area is expected to triple during the same period. This will further increase the energy requirements.

Climate change poses serious threat to urban infrastructure, quality of life, and entire urban systems. Cities need to adopt an integrated approach for improvement of city services in order to adapt to climate change and reduce their greenhouse emissions. Cities need to build enough resilience to respond to extreme events of climate change (for example greater number and intensity of cyclones, heat waves, flooding). A few initiatives which will help the cities to deal with adaptation issues include, inter alia, buttressing of key infrastructure (e.g. increased robustness of water and power supply systems), greater adaptive capacity through buildings and critical infrastructure to withstand increased climate variability [1]. Reduction of greenhouse gas emissions from cities would not possible without major changes in cities including (a) increasing urban density (b) improving urban design to avoid sprawl, (c) improving city public transit, (d) changing building practices, and (e) changing sources of energy [1].

Finance to address climate change is a critical concern for cities. The current available funds for mitigation and adaptation, not limited to cities, only amounts to $\$ 9$ billion per year. The maximum estimated available funding in future for climate change through the UNFCCC and other funds is $\$ 100$ billion per year, which is far less than the estimated requirement of $\$ 275$ billion per year for mitigation and adaptation finance [1]. In view of the extremely limited funding, cities need to find alternative sources of finance to fund the adaptation and mitigation measures. Public private partnerships have a great potential to reduce the burden on local finances and provide the necessary resources to address climate change by promoting green growth in cities.

\section{Public private partnerships and climate change mitigation}

In developing countries, private sector can play a significant role in infrastructure-related climate change mitigation and adaptation programmes through PPP route. In similar line, the National Action Plan on Climate Change (NAPCC) released by Prime Minister of India in June 2008, mainly looks into inclusive sustainable development and inclusion of civil society and PPP in the process [2]. PPP hold great promise for local authorities in building infrastructure for cities to diminish the causes of climate change (mitigation) and effectively protect themselves from its impacts (adaptation) in view of the budgetary constraints and lack of techno-managerial competencies to adopt green technologies. Emerging environment-friendly technologies which are applicable for adoption in urban infrastructure to meet the climate change targets demand great technical expertise and know-how, in addition to large capital availability. The private sector, who specialises in such technologies, could be main drivers for such PPP projects along with the financial institutions to provide the necessary funding to develop these projects.

Public-private partnership (PPP) has been opted by various governments as an alternative form of public procurement. Many countries have adopted PPP on account of different reasons, such as budgetary pressure, inefficient public services to infrastructure, and demand-supply gap. While, some countries have adopted PPP with the expectation of gaining operational efficiency, innovative technological solution, and getting management skills and technical expertise from private sector in delivery of public service.

PPP is a partnership between public sector and private sector for the purpose of delivering a project or service that was traditionally provided by public sector. The private sector side include investors, lenders and companies providing construction and operational services and on the public sector side include public authorities creating and implementing PPP policies as well as those procuring PPP. The parties to PPP have conflicting interests 
and as a result structuring PPP is quite complex as there is a need to reconcile the interests of the parties involved and relationships between them. Public organisations aim at maximizing the social welfare benefits while the private sector is concerned with maximizing their returns. An enabling environment is required for private sector to participate in infrastructure development projects which will limit the risk exposure such that the reward to them is in line with their risk appetite.

Investors to infrastructure projects, which are being implemented to meet the socioeconomic changes, providing private capital undertake rigorous risk analysis to ascertain the risks which could affect the investment goals of the investors. Traditional risks which could be linked to infrastructure projects can be grouped under three broad categories: Policy, political and regulatory risks; Commercial and technical risks; and Business risks (Table 1). These risks associated with the project could affect the financial viability of the projects and these risks are required to be managed beforehand through optimal risk allocation framework, wherein the risks are allocated to the party best able to manage them at the least cost, such that the risk-return profiles are attractive to the private investors. In order to provide an attractive risk-return profile, PPPs are designed with rigid framework comprising of carefully crafted agreements wherein the rights and responsibilities are well defined in advance and mitigating measures incorporated to take care of events which the parties could foresee at the time of drafting the agreement. Security measures are incorporated in PPP arrangements to limit the exposure to wide range of risks which can come into play over the life cycle of the projects. For instance, design risk, technology risk, construction and operation-related risks are mitigated using proven technology with tested construction and operation practices by well-experienced operators. Whereas, risks such as political risk, legal risk, and planning risk are transferred to public partner. However, when climate change has to be integrated with the investment goals in the infrastructure development strategies, the investors are faced with additional challenges that limit the attractiveness of investment in low carbon climate resilient infrastructure projects, such as unsupportive environmental policy backdrop, which distorts the relative pricing of clean versus polluting projects and introduces regulatory risk and uncertainty for private investors; lack of familiarity, information, knowledge and expertise with green infrastructure projects; as well as lack of appropriately structured financing vehicles to provide the risk/return profile that the private sector expect.. These challenges, thus, introduce additional risks linked with climate change aspects of infrastructure projects besides the risks of traditional infrastructure projects (please refer Table 1). 
Table 1. Risks Associated with Infrastructure Projects. [3]

\begin{tabular}{|c|c|c|c|}
\hline $\begin{array}{l}\text { Risk } \\
\text { Category }\end{array}$ & Risk Type & $\begin{array}{l}\text { Traditional risks linked to } \\
\text { infrastructure projects }\end{array}$ & $\begin{array}{l}\text { Additional risks linked to the } \\
\text { climate change aspects of } \\
\text { infrastructure projects }\end{array}$ \\
\hline \multirow[t]{2}{*}{$\begin{array}{l}\text { Political, } \\
\text { policy and } \\
\text { regulatory } \\
\text { risks }\end{array}$} & $\begin{array}{l}\text { Policy and } \\
\text { regulatory } \\
\text { risk }\end{array}$ & $\begin{array}{l}\text { - Lack of political } \\
\text { commitment / policy } \\
\text { certainty over the long } \\
\text { term on infrastructure } \\
\text { planning } \\
\text { - Tariffs regulations to } \\
\text { increase fees with } \\
\text { inflation fall behind } \\
\text { schedule } \\
\text { - High bidding costs } \\
\text { involved in the } \\
\text { procurement process of } \\
\text { infrastructure projects } \\
\text { (lack of clarity about } \\
\text { administrative rules; risk } \\
\text { of corrupt practices); } \\
\text { - Fragmentation of the } \\
\text { market and lack of policy } \\
\text { alignment among across } \\
\text { different levels of } \\
\text { government. }\end{array}$ & $\begin{array}{l}\text { - Lack of long term low carbon } \\
\text { development strategies; } \\
\text { - Trade barriers (tariff and non- } \\
\text { tariff barriers) on green } \\
\text { technologies and/or their } \\
\text { inputs; } \\
\text { - Lack of harmonized } \\
\text { environmental regulations; } \\
\text { - Lack of political commitment } \\
\text { / policy certainty over the } \\
\text { stability of specific forms of } \\
\text { support to green investment, } \\
\text { such as feed- in tariffs. } \\
\text { Instability on the price of } \\
\text { carbon, such as weak or } \\
\text { unstable environmental } \\
\text { regulations; forision fuels } \\
\text { Existence of fossil for } \\
\text { subsidies that make other } \\
\text { investments more attractive to } \\
\text { investors. }\end{array}$ \\
\hline & $\begin{array}{l}\text { Political and } \\
\text { social risk }\end{array}$ & $\begin{array}{l}\text { Opposition from pressure } \\
\text { groups; corruption; Short- } \\
\text { termism of politicians, } \\
\text { limiting infrastructure } \\
\text { planning and investment. }\end{array}$ & $\begin{array}{l}\text { Additional forms of opposition to } \\
\text { specific LCR technologies or } \\
\text { processes, such as carbon capture } \\
\text { and storage or wind farms, sea } \\
\text { walls. }\end{array}$ \\
\hline \multirow[t]{4}{*}{$\begin{array}{l}\text { Commercial, } \\
\text { and } \\
\text { technical } \\
\text { risks }\end{array}$} & $\begin{array}{l}\text { Technological } \\
\text { risk }\end{array}$ & $\begin{array}{l}\text { Includes the risk of } \\
\text { technology } \\
\text { obsolescence or under- } \\
\text { performance relative to } \\
\text { expectations. }\end{array}$ & $\begin{array}{l}\text { Particularly high in the context of } \\
\text { low carbon investments as they } \\
\text { often involve new technologies. } \\
\text { The level of risk will depend on } \\
\text { the maturity of the technology. }\end{array}$ \\
\hline & $\begin{array}{l}\text { Construction } \\
\text { risk }\end{array}$ & $\begin{array}{l}\text { Covering delays in the } \\
\text { completion of the project, the } \\
\text { interface between the } \\
\text { different contracts of } \\
\text { subcontractors } \\
\text { stakeholders. }\end{array}$ & $\begin{array}{l}\text { Lack of expertise in new climate } \\
\text { mitigation and adaptation } \\
\text { technologies. }\end{array}$ \\
\hline & $\begin{array}{l}\text { Operational } \\
\text { risk }\end{array}$ & $\begin{array}{l}\text { Lack of ability for } \\
\text { management and operation of } \\
\text { the asset, and to the } \\
\text { decommissioning of the } \\
\text { project. }\end{array}$ & $\begin{array}{l}\text { Lack of expertise and track } \\
\text { records in new climate mitigation } \\
\text { and adaptation technologies. }\end{array}$ \\
\hline & $\begin{array}{l}\text { Environmental } \\
\text { risk }\end{array}$ & \multicolumn{2}{|c|}{$\begin{array}{l}\text { - Unforeseen environmental hazards linked to an infrastructure } \\
\text { project; } \\
\text { - Climate risk, changing climate can damage the functioning of } \\
\text { infrastructure; } \\
\text { - Risk related to the uncertainty of climate change in } \\
\text { infrastructure for adaptation. }\end{array}$} \\
\hline Market risks & Business risk & $\begin{array}{l}\text { - More competitors } \\
\text { entering the market; } \\
\text { - Change in consumer } \\
\text { preferences and demand. }\end{array}$ & $\begin{array}{l}\text { - Technological advancement; } \\
\text { - Lack of familiarity with new } \\
\text { low-carbon technologies. }\end{array}$ \\
\hline
\end{tabular}




\section{Public private partnership programme in India}

The Government of India has undertaken reforms to create an enabling framework for undertaking PPP projects. The enabling framework along with the fiscal incentives has been partially successful in inviting private sector participation in various urban infrastructure sectors. The reforms have also implicitly indicated the need for adopting both proven and innovative technologies for processing, treatment, and disposal of waste and wastewater. For instance, composting, waste to energy, refuse derived fuel, incineration, pyrolysis/gasification, anaerobic digestion and biomethanation are amongst the technologies suggested for treatment of waste in India. Several PPP waste to energy and compost projects have been developed in various cities wherein the revenue, in addition to tipping fees, from selling the generated power and compost has the potential to improve the financial viability of the project and enable the project to be funded on project finance basis (off-balance sheet). However, these projects have been encountering techno-commercial challenges such as inferior quality and inadequate quantity of the waste, inappropriateness of some of the technologies in the Indian context as the technologies require high level of segregation, high capital cost and O\&M costs of the technologies, and lack of market for the project outputs.

If infrastructure projects are to be developed using private investment through PPP route to meet both the goals of socio-economic development and arrest the climate change effects, then there is a need to review involvement of private sector using the current PPP models in case of climate change related infrastructure projects. Infrastructure projects with the additional goal of climate change mitigation and adaptation would mandate the need for using innovative and emerging technologies and energy efficient practices. Adoption of emerging technologies could cause conflict with the private sector interest of maximizing return and minimizing risks, and scale of infrastructure development to adapt to adverse effects of climate change could affect the project scope and size thereby affecting viability of the project. This demands not only formulation of new strategies to mitigate the risks arising from adopting green technologies but the need to design the reward mechanism so that private sector is attracted to low-carbon, climate-resilient infrastructure PPPs. The main objective of the study is to address the final research question How to incorporate climate change mitigation measures in PPP procurement protocol? The study has focused only on Municipal Solid Waste Management which is one of the urban infrastructure sectors with lot of potential for private sector participation through PPP route.

\section{Procurement process for PPP MSW projects}

The process for procurement of infrastructure projects through PPP route commences with the creation of the procurement team and the process can be considered to be complete with award of the contract to the preferred bidder. This process is undertaken over the phases, namely, Identification, Development, and Procurement stage. The typical procurement process for awarding the PPP MSW projects through the above-mentioned route is shown in Figure 1. Pre-qualification of the bidders is done based on the parameters: technical competency with reference to the experience in previous projects, financial capability with reference to the annual turnover and net worth. The evaluation of the proposals is based on different bidding parameters depending on whether the PPP project is commercially viable or not. For commercially viable projects, the bidding parameters used for proposal evaluation include: a) highest royalty per MT of MSW, b) highest authorization premium per annum to authority. While, for commercially non-viable project, the bidding 
parameters include: a) lowest tipping fee per MT from authority; b) lowest grant from the authority [4].

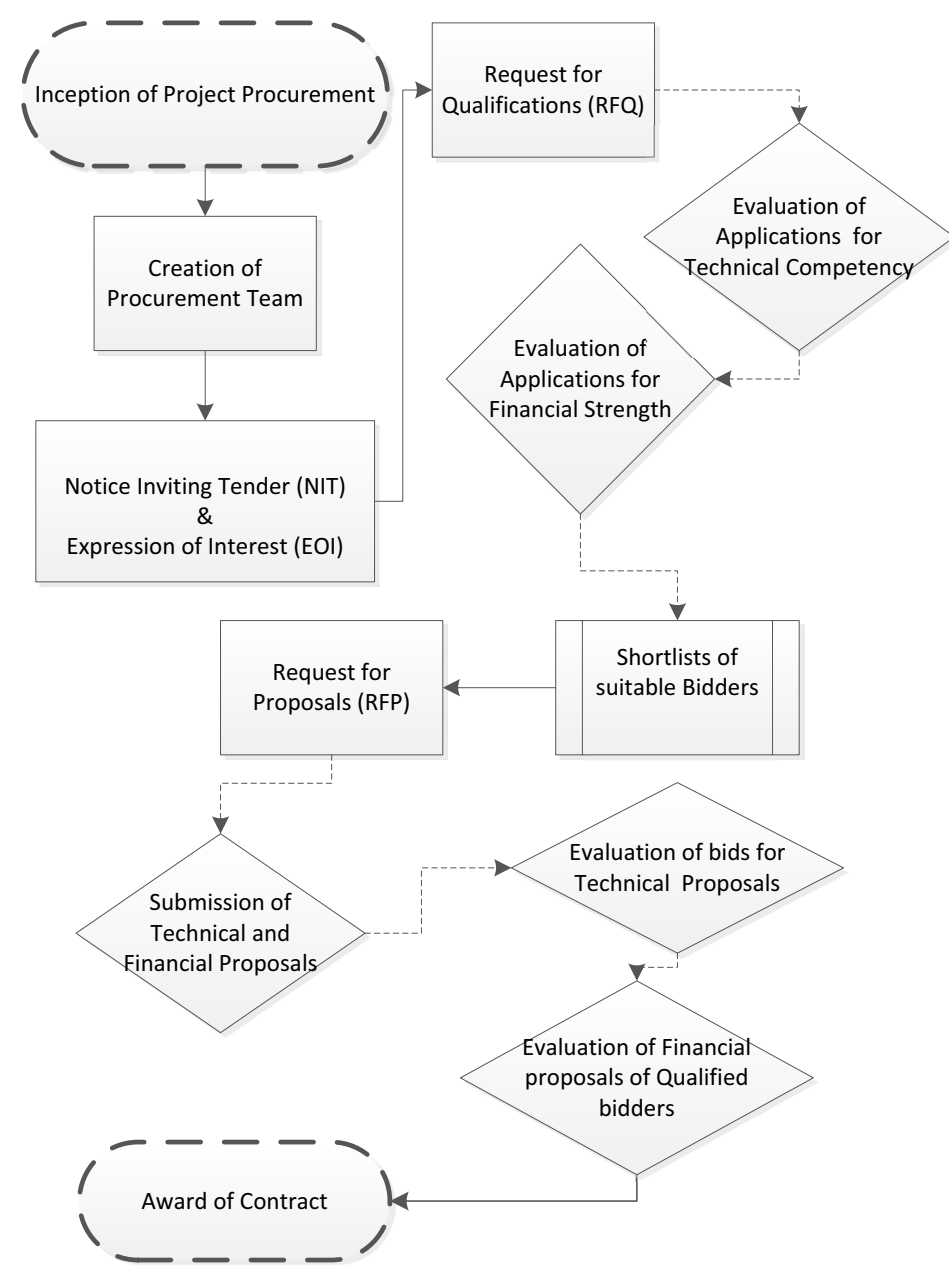

Fig. 1. Step involved in Procurement of MSW infrastructure projects.

The evaluation process of bids adopted in the PPP procurement process has also been critically reviewed to assess the focus of it on climate change (please refer Figure 2). In this model, technical proposals are evaluated in terms of the dimensions such as methodology adopted for the project appraisal, process flow and material balance, resource utilization, operation and maintenance scheme, quality assurance and quality control procedure, time schedule and environmental, health and safety policies. The existing practice of project proposal evaluation does not give too much focus on climate change. Maximum allowable scores are being pre-assigned for each and every parameter relating to the above dimensions. These maximum allowable scores can also be changed by the user depending on the perceived degree of importance of the dimension. The technical evaluation gives an output of the score a bidder gets out of maximum score of 100. A five point Likert scale, varying from 1 being poor to 5 being excellent, has been used for the performance evaluation of the technical proposals with respect to the above-mentioned dimensions. 
Financial evaluation of MSW projects is done based on the assumption that the project is not financially viable. The project is assumed that it will not be able to generate enough revenues to recover the costs. Tipping fee is supported with additional capital grant, normally equaling the lowest capital grant in the bidding process. The preferred bidder is then selected in the final stage based on the composite score, which is the sum of score obtained for technical evaluation and score obtained for the financial evaluation.

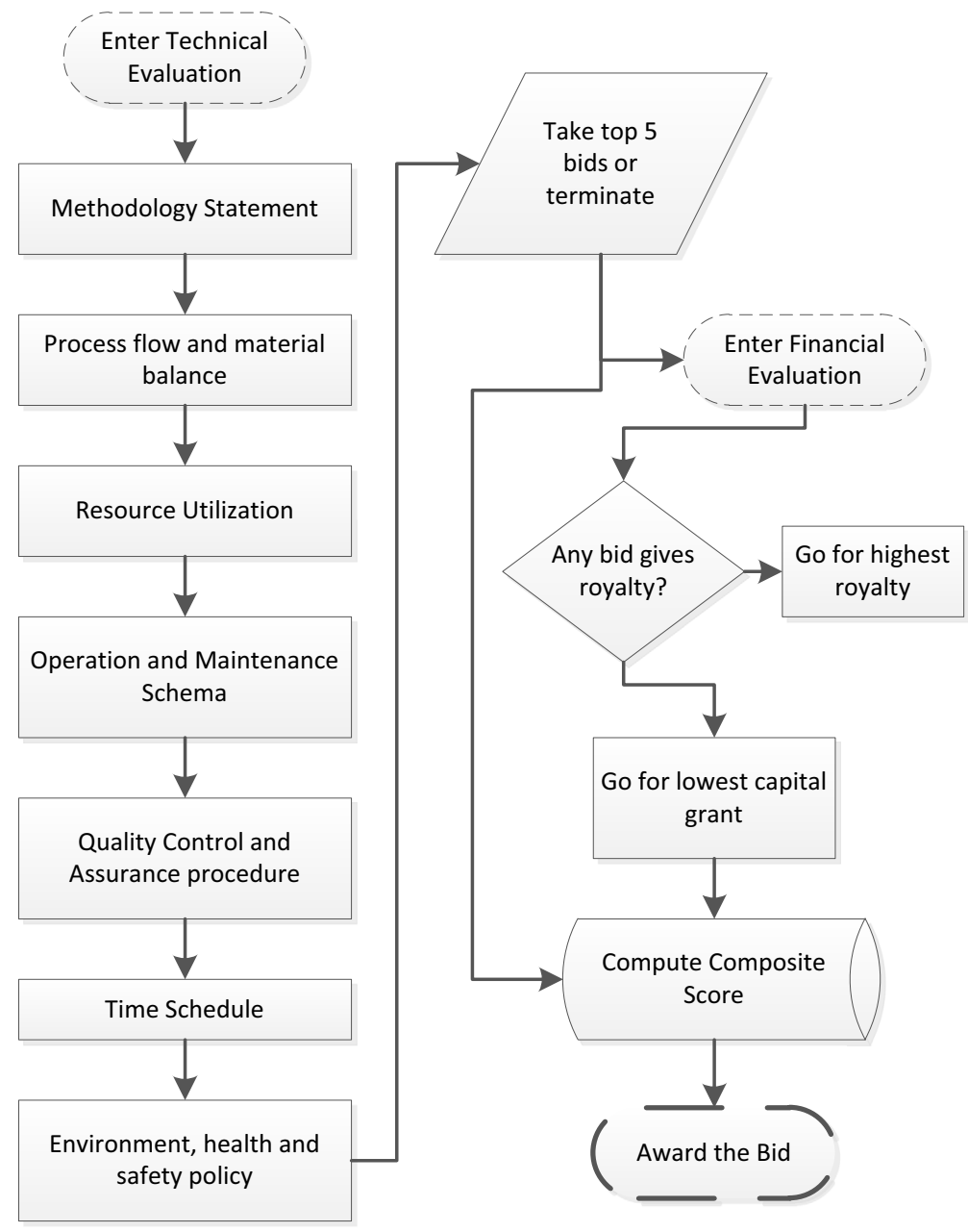

Fig. 2. Evaluation process of bids.

\section{Research methodology}

Case study research strategy suggested by Yin [5] had been adopted to answer the research question. Documents and interviews were the sources of evidence used in the research design of case studies. An introductory appraisal of the research is presented to the prospective interviewees and positive responses were interviewed in person. Semi structured interview template is employed to guide the interview process and to act as a reminder. The process of interview is conversational in manner and the interviewee and interviewer exercised liberty to go beyond the intended questions. Answers were hand 
written for transcription purposes. The interviews lasted for a minimum of 1 hour to 3 hours in a single stretch. In addition to the interview, field visits to site of operations, conversations with site in-charges, and NGOs carrying out the waste collection were carried out to gain in-depth knowledge and understanding of the project, process as well as to validate the strategies to overcome the hurdles. At least 10 hours of interviews were carried for each project included in the case studies.

Current study followed the research procedures established by [5-7]. The interview data is analyzed with a qualitative software Nvivo [Version 10] developed by QSR International [8]. Qualitative data is marked by its nature of depth of the subject the people involved. The process followed in analysis of the interview data has been drawn heavily from [6] and [7]. The case study analyses adopted for the study is based on the recommendations of Yin (2009). The interviews were verbally transcribed and were fed into Nvivo software. The same person had administered the interview and performed coding thereby eliminating the error of 'coding variance'. Analysis of the interviews have been done using 'hypothesiscoding' method in first stage of the analysis [6, 7]. Since the research didn't have a grounded theoretical propositions, 'developing case descriptions' strategy was employed in 'explanation building' analytic technique as recommended by Yin [5]. Creating codes followed a deductive approach from the literature review, hypothesis and the variables that we intend to observe. Each node holds the information about a variable or process intended to be observed. These first nodes are further refined to yield the pattern codes. The objective of pattern coding is to condense the amount of data into small and manageable units. Narrative 'rich' description is considered the most appropriate for current research objective Yin [5]. Finally, the output of the case analysis is presented in narrative and the application developed is presented in matrix displays in the culmination of all case studies.

\section{Modified procurement protocol}

The case study analysis has highlighted that the procurement process being used by the various local government for procurement of PPP projects in India suffers from various setbacks if the procurement process is to be designed to promote infrastructure development along with the goals of climate change mitigation. Some of the major limitations of the existing procurement protocol from climate change mitigation perspective are as follows:

1. No opportunity to innovate, as the procurement is predominantly prescriptive rather than output oriented.

2. No interlinking of payment mechanism and hence poor control on contract management.

3. No integration of incentive mechanism and promotion of private sector to optimize.

4. No emphasis on recycling.

5. The objective of climate change mitigation has not received its required utmost attention.

6. It assumes bundling of activities as a means of obtaining efficiency.

Based on the feedbacks from the case study, a modified procurement protocol has been devised. The modified procurement protocol is shown in Figure 3. The principles and objectives governing the modified procurement protocol to promote both infrastructure development and climate change mitigation other than what is already existing are outlined as follows:

1. Promotion of low carbon technology for effective reduction of GHG emissions from all the process involved in the project is of main emphasis. 
2. Best value in this context of infrastructure not only mean financial sustainability but also project which meets the need by providing service which is both sustainable and utilized the low carbon technology.

3. Modified procurement protocol facilitates, promotes, and incentivizes the private sector for emission reduction in appropriate manner.

4. Payment mechanism should be robust enough to capture the necessity of service levels of the project as well as high remission reductions.

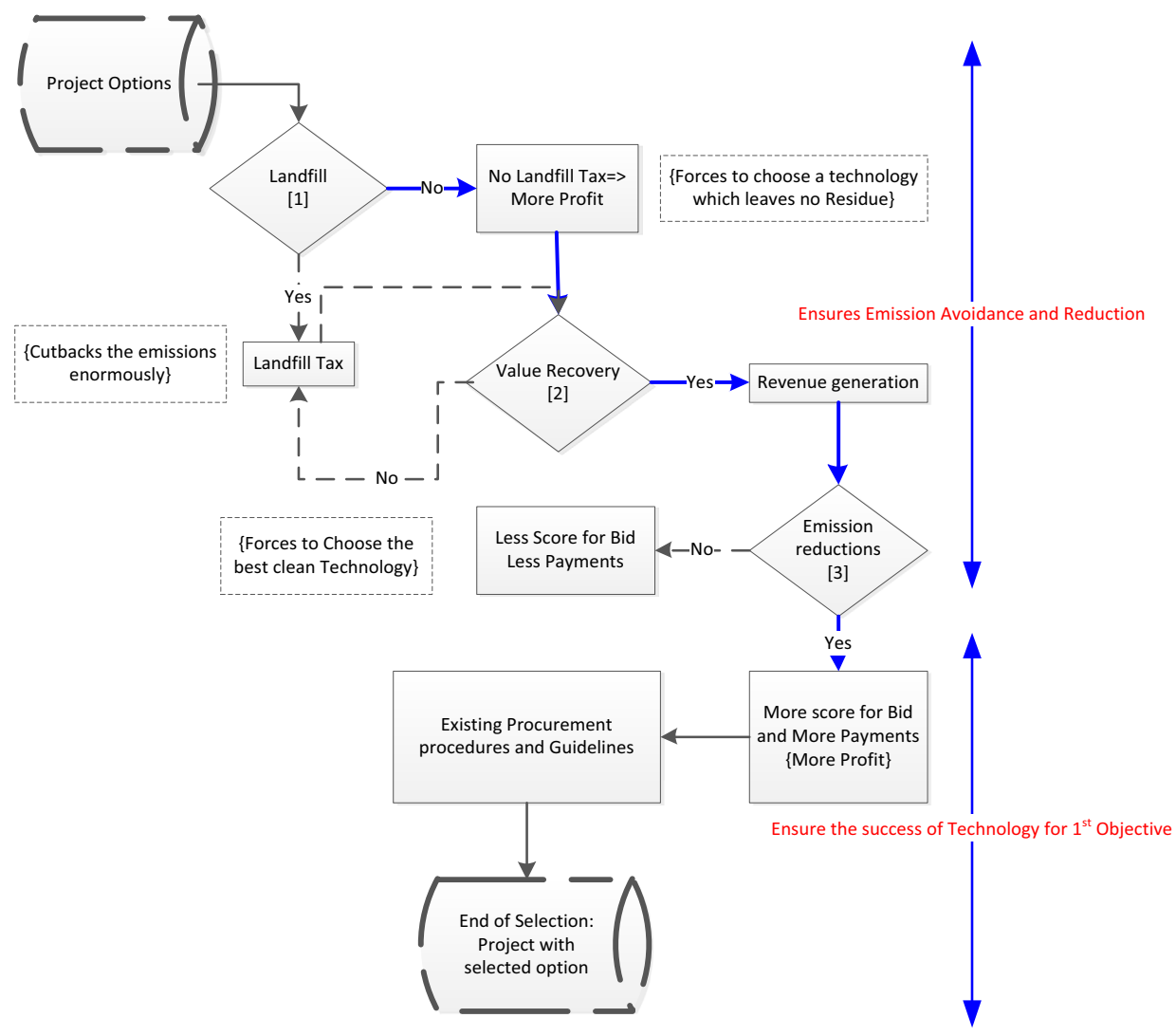

Fig. 3. Modified Procurement Process for PPP MSW Projects.

Performance based payments are recommended and the performance is measured according to the emission reductions. Any changes occurring during the asset life because of technological advancements, adaptation or modified usage can be incorporated to facilitate emissions reduction. However, the incentive is only limited to the performance payments. The rational of the new protocol is to promote the usage of clean technology and in mitigating GHG emissions and the rationale for the modified framework is based on the following concepts:

Landfill, material recycling, and emission reductions: The importance of each category can be viewed in terms of all the dimensions of sustainability. Carbon pricing comprises of two components: (i) carbon tax, and (ii) emission trading schemes [9]. From sustainability perspective, economic sustainability of landfill can be looked in terms of the value of the land consumed instead of some other opportunity value, environmental sustainability with respect to the methane emission that are caused from the material going into it, whatever 
insignificant quantity may be, and social sustainability with respect to the social discomfort caused by the site it at all any. The desired direction of procurement process could be as follows: A landfill tax on the private entity for dumping the waste into the sanitary landfill could force him to innovate and build facilities from time to time that will force him to divert the waste from landfill. In such case, a no tax scenario itself is the profitable scenario so that the process brings legitimacy. In spite of the agreement of respondents on the philosophy of landfill tax, the applicability of such methodology is being questioned owing to the factors like large number of small-scale projects or distributed project in a city. Implementation of landfill tax requires unbundling of the package 'construction of sanitary landfill and operation' amongst the various PPP players. Though such bundling might be possible, the responsibility of landfill care is vested with the public sector in US, where this model is widely used.

Similarly, material recovery has an unseen, unharnessed potential, which is often less communicated or underestimated. The more we recycle the items with high emission potential, lesser will be the impact on emission of the whole project. Even though the direct emission reduction is low for steel and aluminum, huge reduction in GHG is possible if the virgin products are replaced with recycled products. This is referred as downstream emissions or indirect emissions. Task force setup by GOI strongly recommends the diversion of at least $75 \%$ of waste from landfill using appropriate technologies [10]. It should be noted that recycling and source segregation is the key while technology can provide additional support for diversion rates.

Furthermore, quantitative emission reduction measurement is of utmost importance and it is the crux of low carbon pathways. This helps in setting the benchmark and investing in much lower technologies in future. However, the critical concern here is that unless the benefit or reward that a private sector can accumulate over years is greater than the investment it may require to bring in much more efficient systems, the private sector may settle with the business-as-usual scenario in comparison to the opportunity cost. This demands a rewarding mechanism based on the objective emission reduction the project is achieving in a given financial year. A payment mechanism in terms of rupees per $\mathrm{tCO}_{2} \mathrm{e}$ reduced from the project scenario will help and encourage the private sector to always innovate and bring new potential measures even in the contract management phase. This, paradigm of performance-based payments is entirely different from the payment mechanisms being used in conventional project scenario. However, owing to the high competency levels required in public sector in spite of wide range of transient competency enhancement strategies used in India like transaction advisors, these kind of dynamic payment mechanisms require higher competency levels in public sector organizations also. Much rigorous studies are further needed to guide the ULBs and PPP coordinating agencies in order to implement such kind of payment mechanism.

\section{Conclusions}

Development of urban infrastructure using private sector participation has been widely adopted by various cities to create a sustainable built environment. Private sector participation has been sought by the governments to supplement the scare budgetary resources in the light of increasing infrastructure demand-supply gaps. Furthermore, the rationale for widespread private sector participation in urban infrastructure development is based on the efficiency gains brought by their participation. Through well-designed procurement protocol, public private partnership approach has the potential to promote innovative solutions for infrastructure development.

Public private partnerships have huge potential for incorporation of climate change mitigation measures besides providing quality infrastructure services. The current 
procurement process being used by Indian Government for private sector participation in development of MSW projects has been studied through case study research approach to study the extent to which it promotes climate change mitigation measures besides infrastructure development goals fulfilment. The current procurement process has limitations in promoting this objective and to overcome this a modified procurement protocol has been formulated based on the inputs from the case study research. The modified protocol incorporates criteria that will encourage them to incorporate measures for climate change mitigation while structuring MSW projects to be developed through PPP route. This procurement protocol, however, needs to be studied in depth to examine its applicability.

The authors appreciate the support received from HUDCO's Human Settlement Management Institute (Research and Training Wing of HUDCO), New Delhi for carrying this research. The views expressed herein are those of the author and not necessarily those of the HSMI, HUDCO.

\section{References}

1. World Bank, Cities and climate change - An urgent agenda, in Urban Development Series - Knowledge papers. 2010, The World Bank: Washington DC.

2. Government of India. National Action Plan on Climate Change. 2008 [Accessed on 2012 August 18]; Available from: pmindia.nic.in/Climate\%20Change.doc.

3. Kennedy, C. and J. Corfee-Morlot, Mobilising investment in low carbon, climate resilient infrastructure. 2012, OECD: Paris.

4. MoUD, Model RFP for ISWM on PPP-BOT: Volume 1 Instruction to Bidders. 2010, Ministry of Urban Development, Government of India: New Delhi, India.

5. Yin, R.K., Case study Research. 2009, Thousand Oaks, California: SAGE Publications, Inc.

6. Miles, M.B., M, H., \& Saldana, J. (2014). Qualitative Data Analysis: An Expanded Sourcebook 2014, Thousand Oaks, California: SAGE Publications, Inc.

7. Saldaña, J., The Coding Manual for Qualitative Researchers. 2011, Thousand Oaks, California: SAGE Publications, Inc.

8. QSR, Nvivo 10. 2012, QSR International Pty. Ltd.: Melbourne.

9. ADB, Policies and practices low- carbon green growth in Asia. 2012, Asian Development Bank: Phillippines.

10. Planning Commission, Report of the Task Force on Waste to Energy. 2014, Planning Commission, Government of India: New Delhi. 